\title{
Evaluation of Horizontal Equity under a Distance-Based Transit Fare Structure
}

\author{
Milad Bandegani and Meisam Akbarzadeh \\ Isfahan University of Technology, Iran
}

\begin{abstract}
Horizontal equity requires equal distribution of investment/benefit/costs among equal members of society. In other words, a transit passenger should pay as much as he/she uses. This study evaluated the measure of fulfillment of this rule in a case study, developed a distance-based fare structure, and shows that justice is better served by switching to the proposed structure. Fare elasticity of demand and probability distribution of transit passenger trip lengths were investigated through a field survey. Although mainly used in the measurement of inequality in income or wealth, the Gini index and the recovery ratio (revenue to cost for each transit passenger) in evaluating equity were used in this study. Results show that the Gini index would decrease from 0.38 to 0.17 after switching from a flat to a distance-based structure. Assessment of the ratio of revenue per mile over cost per mile (RPM/CPM) shows that switching to a distance-based fare structure makes the $R P M / C P M$ curve significantly flatter, which indicates more similarity among passengers. As a byproduct, the amount of change in demand and revenue of the transit system also were formulated.
\end{abstract}

Keywords: Equity, elasticity, fare structure, Gini index.

\section{Introduction}

This study aimed to quantify the effect of distance-based fare structure on horizontal equity in public transportation systems. Equity may be defined with respect to the distribution of the system's costs, benefits, or both among users (Pucher 1981). Access/ egress time, waiting time, and monetary cost are the main impediments to public transportation ridership. Benefits of a public transportation system include accessibility and subsidy in payments. An extensive study of equity in public transportation systems should include all these elements. This study, however, focused on the monetary cost, since other factors are not expected to be sensitive to fare structure.

From economic and social points of view, equity is divided in two categorieshorizontal and vertical. Horizontal equity requires equal treatment of equals, i.e., one 
pays as much as one uses/takes. Vertical equity, on the other hand, requires distribution of costs and/or benefits according to the users' need for the service or their capability for payment.

Two general structures of fare calculation are flat and graduated. In a flat structure, the fare of a line is predetermined and, therefore, is not sensitive to passenger trip characteristics (length, time, etc.). In a graduated fare structure, the fare rate may be dependent on a trip characteristic (length, time, zone, etc.) (Grey 1975; Nash 1982; Lovelock 1987).

From an organizational perspective, fare influences ridership and ridership determines revenue. To quantify the process, an acceptable estimate of price elasticity of demand is needed. Price elasticity of demand is the percentage of change in demand for a good or service as a result of a $1 \%$ change in its price. Therefore, elasticity establishes the relationship between fare and demand. Revenue, on the other hand, is the sum of all fares paid by passengers. In other words, price elasticity measures the rate of response of quantity demanded due to a price change and shows that percentage change in quantity demanded versus a $1 \%$ change in price.

Technological advances such as automatic fare collection (AFC) and automatic vehicle location (AVL) systems have paved the way for implementing distance-based fare structures. By using a ticket card upon boarding and alighting, the location and distance of a passenger's trip can be calculated, and the amount of fare can be determined accordingly. This process adds a few seconds to the station operation for each passenger but brings great benefits in terms of equity and cost incurred by passengers.

\section{Literature Review}

\section{Fare Elasticity}

Fare elasticity has a rich literature in which relationships between fare and transit operational factors are investigated. Fare elasticity is a fundamental parameter to estimate demand and income before any change actually occurs in the amount of fare. Some previous studies have investigated the effect of fare change on demand in the long and short terms (Dargay and Hanly 1999; Goodwin 1992). Litman (2015) concluded that the fare elasticity of transit ridership in the short term varies between -0.2 and -0.5 and in the long term varies between -0.6 and -0.9. Nowak and Savage (2013) assessed the cross elasticity between the price of gasoline and transit ridership in Chicago and found that it was small (about 0.05 ) when gas prices are under \$3/gallon. When gas prices exceed $\$ 3 /$ gallon, elasticity for rail-based transit modes is in the range of $0.12-0.14$, and when gas prices exceed $\$ 4 /$ gallon, elasticity is in the range of $0.28-0.38$. Sirikijpanichkul and Winyoopadit (2013) investigated the price elasticity of demand for travelers of different ages and travel distances in Bangkok and found that passengers older than age 45 traveling long-distance trips have a higher price elasticity of demand than young and short-distance passengers. Wardman and Grant-Muller (2011) reported the price elasticity of the demand for excursion trips to be greater than business trips. 
Wang et al. (2015) used metro smart card data of Beijing to evaluate the fare elasticity of demand and revenue and found that the elasticity of demand for short-range trips $(<5$ kilometers) was more than longer trips.

Smith (2009) presented nine leading factors affecting the price elasticity of transit demand as user type, trip type, geography, type and direction of price change, time frame, distance, transit type and time of a day. Clements (1997) evaluated the response of dependent and discretionary transit riders and found that elasticity values of dependent riders tend to be significantly lower than discretionary riders. Linsalata and Pham (1991) conducted a study of 52 transit systems within the United States and determined the price elasticity in large and small cities for peak and off-peak hours. Their results showed that demand was less price-elastic during peak hours and in large cities. Horn af Rantzien and Rude (2014) assessed the price effects on the demand for public transport in peak- and off-peak periods in Stockholm; their results showed higher elasticities during off-peak periods compared to peak periods.

\section{Fare Structures}

Fare structures in public transportation include flat and graduated fare structures. Flat fares can be converted into variable fares based on factors such as distance, time, quality, cost, region (zone), and customer. A distance-based structure is based on the length of the trip. In a time-based fare structure, the amount of fare is determined based on trip duration or its occurrence during peak or off-peak hours. In cost-based pricing, the amount of fare is determined according to the cost incurred by the system to supply the service. In a zonal-based fare structure, the fare amount is determined based on the distance across zonal boundaries. In a customer-based fare structure, the fare rate is calculated according to the characteristics of the user, such as age and economic status.

\section{Social Equity in Public Transportation}

The importance of social equity together with a transportation system's profound impact on the fulfillment of equity has led to a significant amount of research in this regard. Related research focuses either on geographical distribution of transit benefits or on demographic distribution of transit costs. As an example of the first group, Welch and Mishra (2013) combined parameters including frequency, speed, and capacity of passing lines to introduce the power of each station and analyzed the distribution of transit power throughout an urban area using Gini index. Ricciardi et al. (2015) explored public transport equity for older residents, low-income households, and no-car households and compared the status of two major Australian cities.

As a seminal study in the second group, Cervero $(1981,1990)$ and Cervero et al. (1980) evaluated the efficiency and equity implications of alternative transit fare structures. They define pricing structures as being efficient when users contributed to the costs of their services in line with the benefits they receive, as reflected by the marginal costs of their trips. On the other hand, fares are considered equitable when they take into 
account the income capacities of riders. To inspect the effect of fare structures on groups of transit passengers, farebox recovery ratio was used as the ratio of fare price over the cost per passenger-mile. An example of a recent study within the second group is Farber et al. (2014), who incorporated a joint ordinal/continuous model of trip generation and distance traveled into a GIS Decision Support System. Applying this method to Wasatch Front, Utah, revealed that, overall, distance-based fares benefit low-income, older adult, and non-white populations. However, the effect was geographically uneven and even might be negative for members of these groups living on the urban fringe.

\section{Methodology}

This paper makes its contribution to the current body of literature by developing a mathematical foundation for a distance-based fare structure and systematically investigating its effect on horizontal equity.

To evaluate the effect of fare structure on equity, three steps should be taken: 1) price elasticity of transit demand should be estimated; 2) a formulation for fare structure should be developed; and 3) a reasonable framework for evaluating the equity should be developed.

As shown in Equation 1, price elasticity of demand $\left(\varepsilon_{p}^{D}\right)$ is measured by the percentage of change in demand $(D)$ as a result of $1 \%$ change in fare $(p)$.

$$
\varepsilon_{p}^{D}=\frac{\partial D}{\partial p} \times \frac{p}{D}
$$

To fulfill the first requirement, a survey was conducted among transit passengers in Isfahan, a city of 1.7 million located in central Iran.The sample size included 300 passengers of 6 major lines of the bus transit system. Respondents were asked how much they were paying for fare and how much more they were willing to pay before switching to alternative modes, if any (consumer surplus). Data were collected during both peak and off-peak time periods. It is noteworthy that the Isfahan bus transit network is composed of 97 lines with an approximate length of $2 \mathrm{~K}$ kilometers serving $900 \mathrm{~K}$ passengers daily, which makes its share in the city's transportation equal to $20 \%$. The transit lines all over the city are mostly radial and circumferential. Currently, the fare of each line is determined based on length. All the buses serving the Isfahan transit network are equipped with an AFC system; hence, a distance-based fare structure is implementable.

Comparison of the consequences of fixed and distance-based fare structures requries establishment of the mathematical relationship between the two structures. In a distance-based structure, the fare for traveling through i stations $\left(F_{i}\right)$ consists of a fixed "flag-fall" charge $\left(F_{0}\right)$ and a unit line haul charge per segment $\left(F_{l}\right)$, where a segment is defined as the distance between two consecutive stations. Therefore, the fare would be calculated from Equation 2.

$$
F_{i}=F_{0}+(i-1) F_{1}
$$


Without loss of generality, it could be assumed that in a fixed fare structure, the fare $\left(F_{F l a t}\right)$ is equal to the amount of fare for traveling through the whole line divided by a factor $K \in \mathbb{R}$. Hence, if $n$ denotes the number of all stations in a line, the flat fare ( $\left.F_{\text {Flat }}\right)$ can be formulated as Equation 3.

$$
F_{\text {Flat }}=\frac{F_{0}+(n-1) F_{1}}{K}
$$

Therefore, by switching from a fixed to a distance-based fare structure, a passenger traveling $i$ stations would experience a change in fare equal to $\Delta \mathrm{F}$ :

$$
\Delta F=F_{i}-F_{\text {Flat }}=\frac{(k-1) F_{0}+[k(i-1)-(n-1)] F_{1}}{K}
$$

From the definition of elasticity, it is evident that the percentage of change in demand $(\Delta D \%)$ is equal to the percentage of change in fare $(\Delta F \%)$ multiplied by the fare elasticity of demand $(\varepsilon)$. On the other hand, the percentage of change in the fare amount is the sum of the fare change for trips with length of $i$ stations. Hence:

$$
\Delta D \%=\Delta F \% \cdot \varepsilon=\sum_{i=1}^{n} \frac{F_{i}-F_{\text {Flat }}}{F_{\text {Flat }}} \cdot \varepsilon_{i}
$$

Therefore, demand under distance-based fare structure $\left(D_{D-B}\right)$ can be calculated from Equation 6.

$$
D_{D-B}=D_{\text {Flat }} \cdot(1+\Delta D \%)
$$

To assess the financial consequences caused by the change in fare structure, the amount of revenue must be analyzed. Equation 7 shows the change caused by switching from a flat-fare to a distance-based fare structure $(\Delta R)$.

$$
\Delta R=\sum_{i=1}^{n}\left[D_{D-B}(i) \cdot F_{i}-D_{\text {Flat }} \cdot F_{\text {Flat }}\right]
$$

\section{Assessment of the Fairness of Fare Structures}

Disparity between a passenger's benefit (trip length) and cost (fare) implies inequality. Revenue per Mile (RPM) is the revenue from fares, and cost per Mile (CPM) is the cost incurred by the system. RPM/CPM would show if passengers are paying more than they benefit from the transit service or vice versa. This factor also measures the share of each user's trip cost covered by a rider's fare. Under the condition of perfect equity, the value of RPM/CPM would be equal to 1 for all trip lengths.

Based on value of RPM/CPM, two distinct types of evaluations were carried out. First, the distribution of RPM/CPM among the passengers with different trip lengths was analyzed. At perfect equity, the ratio of RPM/CPM is equal to 1 for all passengers regardless of trip length. Second, the distribution of RPM/CPM among the population of passengers could be analyzed and its fairness can be assessed via the use of Gini index. A Lorenz curve was used for assessing the uniformity of the distribution of benefits among the passengers. A Lorenz curve plots the cumulative percentages of total received benefit versus the cumulative number of recipients. The area between the Lorenz curve and a hypothetical line of absolute equality is the Gini index value. The Gini index $\left(G_{a}\right)$ 
measures the extent to which the distribution of an entity among units of concern deviates from a perfectly equal distribution. This number ranges between 0 (perfect equity) and 1 (perfect unequity) and is calculated using the following formula where $X_{k}$ is the cumulative proportion of the population and and $Y_{k}$ is the cumulative proportion of attribute $k$.

$$
G_{\alpha}=1-\sum_{k=1}^{m}\left(X_{k}-X_{k-1}\right) \times\left(Y_{k}+Y_{k-1}\right)
$$

\section{Case Study}

Price elasticity of transit demand was calculated for different categories of passengers based on survey data. Passengers were categorized based on gender, income, trip distance, age, usage frequency, and available alternative mode. Results show that price elasticity was -0.33 and -0.3 for male and female passengers, respectively. The average fare elasticity for passengers younger than age 18 was -0.17 compared to -0.28 for respondents ages $18-40$ and -0.4 for respondents ages $40+$. Analysis showed that price elasticity falls as income increases. The average elasticity for passengers from households with a monthly income below $\$ 330$ is -0.36 compared to -0.32 for $\$ 330-\$ 660$ and -0.24 for whose household income was above $\$ 660$. Results of the survey also indicated a difference pertaining to an available alternative mode. The elasticity value for passengers who had a private vehicle at their disposal was -0.3 . The values for passengers indicating bicycle as their alternative was -0.27 , for taxi -0.3 , for motorcycle -0.42 , and for walking -0.48 . The price elasticity value for passengers who use a bus every day was -0.33 , for "often" users it was -0.25 , and for "seldom" users it was -0.36 . Results also show that elasticity is higher during off-peak hours compared to peak hours.

Since this study was based on trip distances, more elaboration was made on the demand elasticity of passengers with different trip lengths. Using collected data, price elasticity of demand for trips of length $i\left(\varepsilon_{i}\right)$ was estimated. Figure 1 shows the data and Equation 9 shows the calibrated formula with coefficient of determination $\left(R^{2}\right)$ equal to 0.67 .

$$
\varepsilon_{i}=-0.6 e^{-0.06 i}+0.7 e^{-0.3 i}
$$


FIGURE 1.

Price elasticity of demand based on trip length

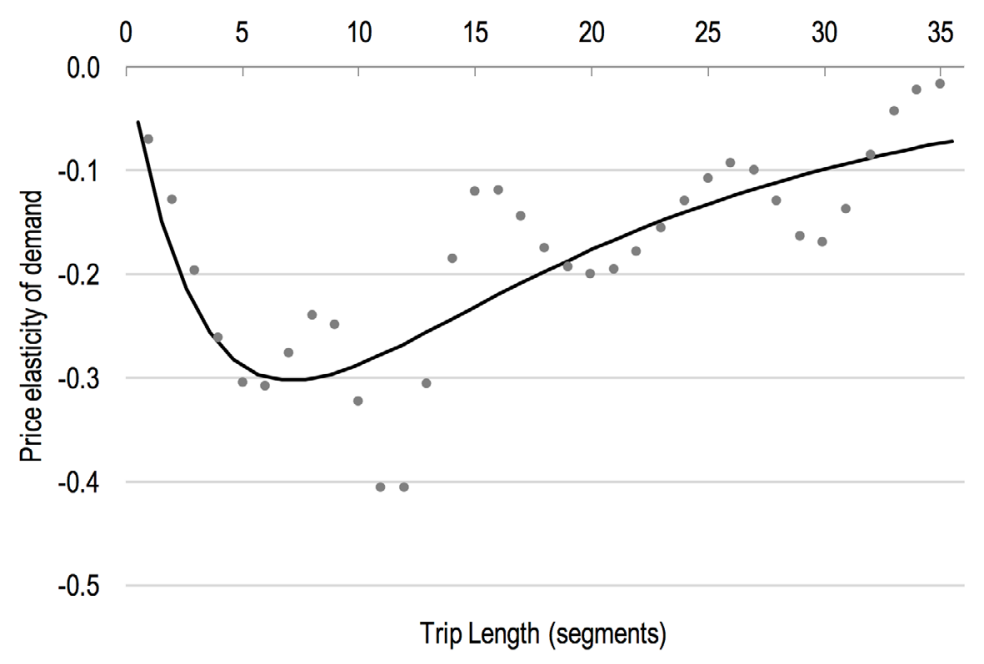

The trip distribution was derived from the survey data and is presented in Equation 10 and Figure 2.

$$
D=\sum_{i=1}^{n}\left(24.1 e^{-\left(\frac{i-6.4}{2.9}\right)^{2}}+18.1 e^{-\left(\frac{i-11.8}{2.3}\right)^{2}}+6 e^{-\left(\frac{i-16.5}{10.6}\right)^{2}}\right)
$$

FIGURE 2.

Frequency of trip lengths

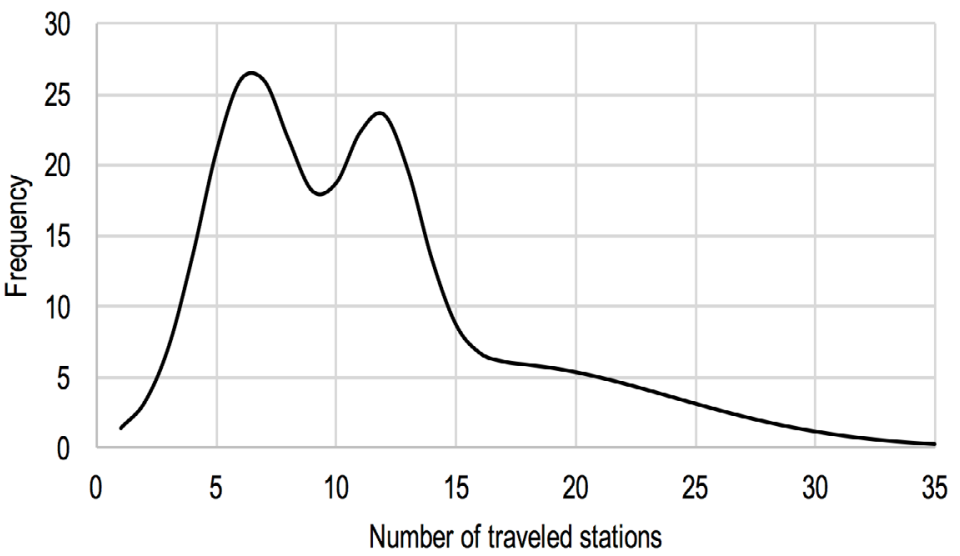

\section{Equity and Fairness of Distance-Based Fare Structure}

Total revenue was calculated by summing the product of demand and fare for each class of trip length. A unique value was assumed for the cost of traveling each segment. Figure 3 shows the Lorenz curve for fixed and distance-based fare. It is evident that by switching from a fixed to a distance-based fare structure, the Lorenz curve moves toward the bisector (complete equity). This merge could be quantified by the value of the Gini Index. The Gini index in fixed and distance-based fare structures was calculated to be 0.38 and 0.17 , respectively. Hence, the Gini-index value declined after switching to a distance-based structure and, therefore, justice is better served. It should be noted that this figure is drawn $F_{\text {int }}=\$ 0.13, F_{0}=\$ 0.033$, and $F_{1}=\$ 0.007$. Values were calculated 
in local currency and transformed to US dollars. According to the Isfahan Bus Transit Organization, the cost of each passenger is about $\$ 0.13$. Since this value is the same for all lines and passengers, it does not affect the methodology. However, it affects the prescribed values for parameters of the formulation, e.g., $F_{0}$ and $F_{1}$.

Figure 3 shows the difference between each fare structure and the full equity condition. In this figure, abscissa and ordinate represent the percentile of the population and the portion of the total value of the RPM/CPM respectively (Welch and Mishra, 2013).

FIGURE 3.

Lorenz curves for fixed-fare and distance-based fare structure
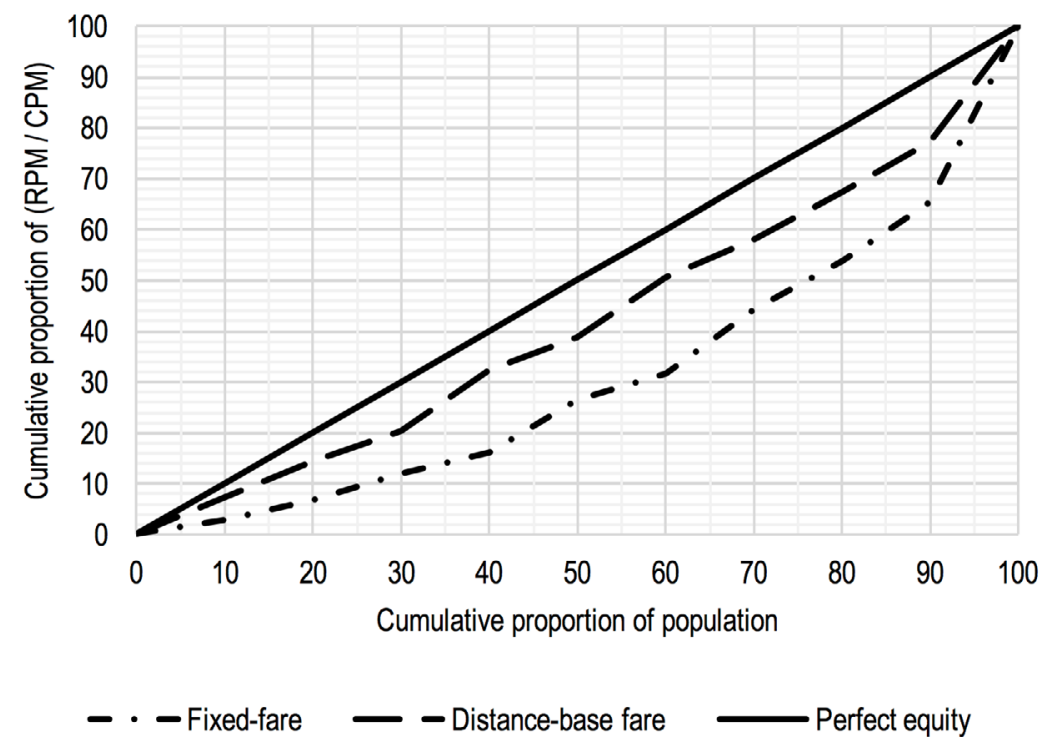

The value of the ratio of RPM/CPM on all segments is depicted in Figure 4. The horizontal dashed line shows the perfect status for equity, the "subsidy threshold" (Cervero 1981). This threshold shows the situation in which every group of passenges compensates for the charges they incur to the system.

4

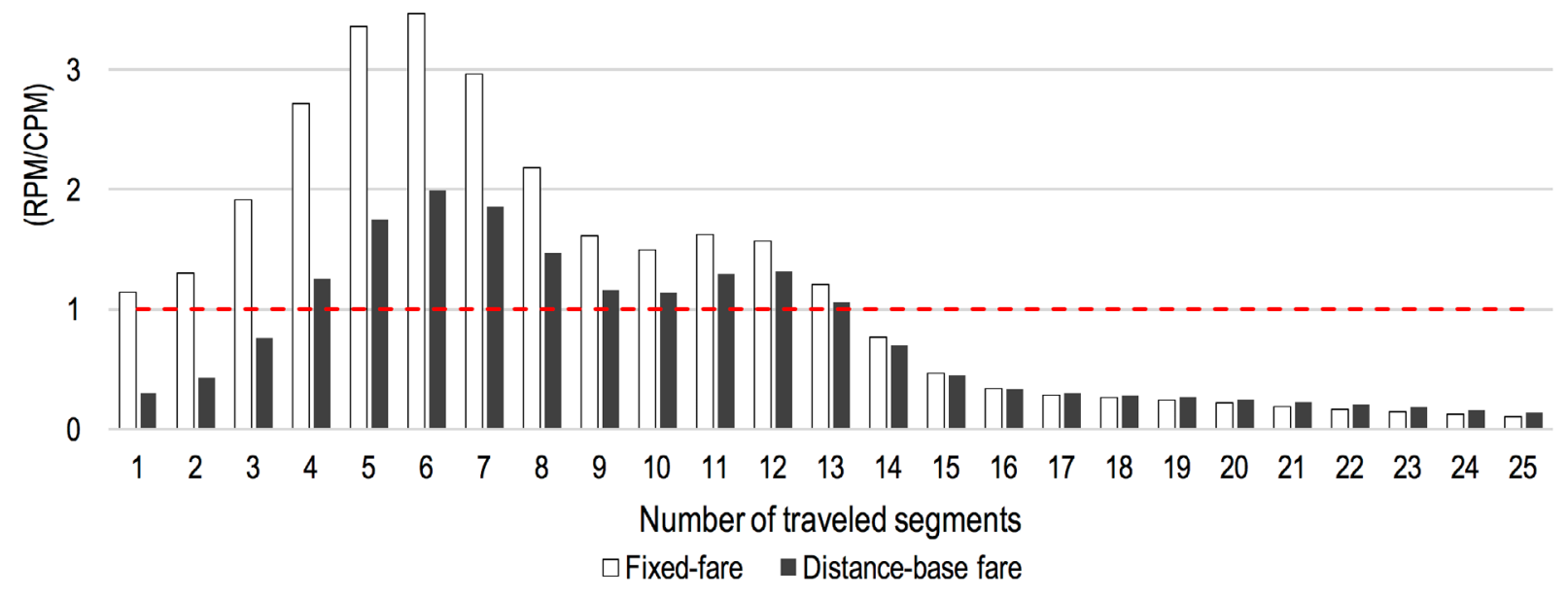

FIGURE 4. RPM/CPM for different trip lengths 
Figure 4 demonsrates that under the current fare structure, passengers with short and medium trip lengths (trip lengths between 2 and 12 segments) are paying more than what they gain (white bars). On the other hand, passengers with longer trip lengths (trip lengths above 14 segments) are paying much less than what they gain. Actually, one group of passnegers is paying the cost of the other. In a distance-based fare structure, this unevenness is modified to a great extent (gray bars). It is evident that the deviation from the dashed line (perfect equity) has diminished considerably.

To quantify the effect of the change, absolute errors were calculated according to Equation 10. It was shown that the absolute error (absolute value of RPM/CPM minus 1) has decreased from 22 (under the current fare structure) to 14 (under the proposed distance-based fare structure), a more than $50 \%$ improvement.

Figure 5 shows how the unevenness of RPM/CPM is distributed among passengers based on their trip length. Comparing the bars shows that by switching to a distancebased structure, unevenness diminishes, especially for trip lengths between 5 and 15 stations which, according to Figure 2, constitutes the majority of passengers.

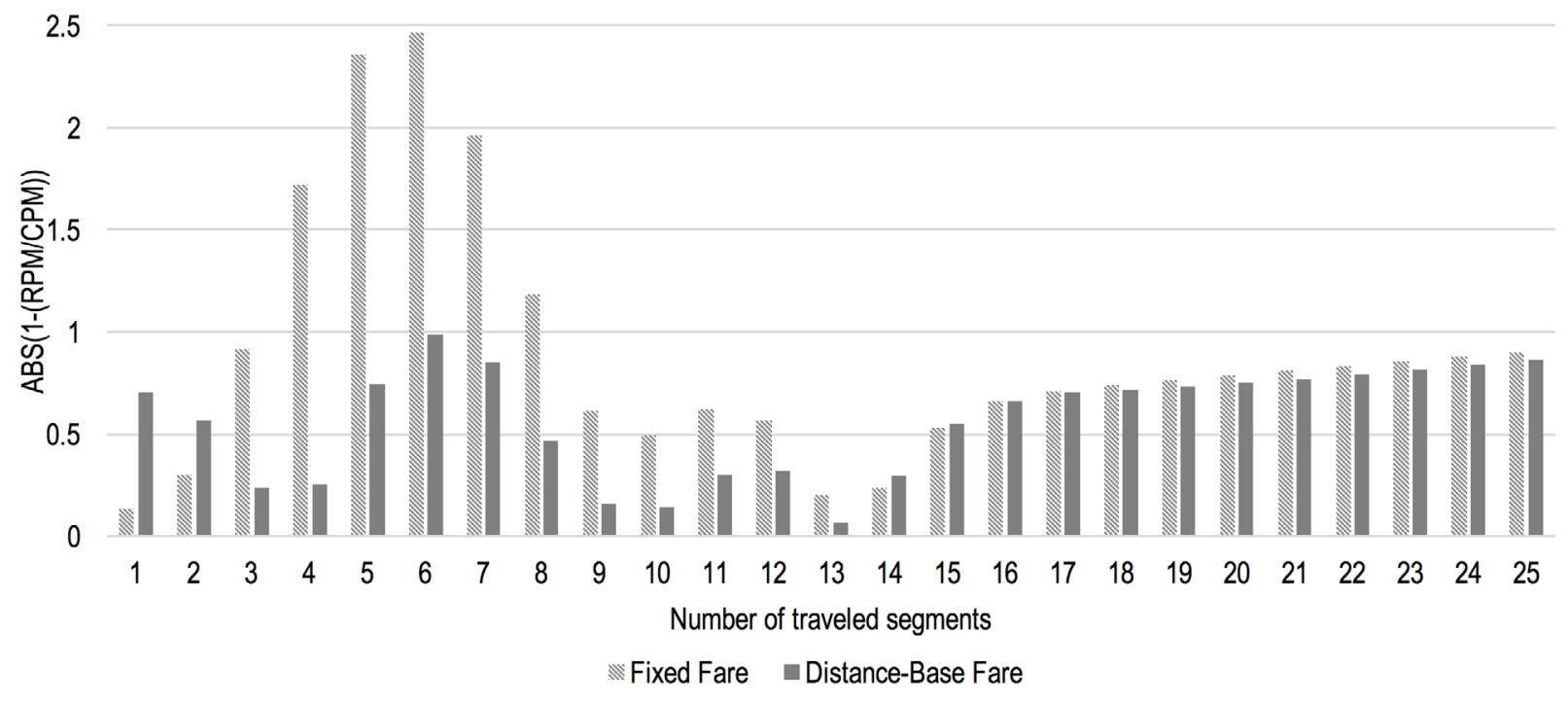

FIGURE 5. Deviation from equity for different trip lengths

\section{Conclusion}

The effect of a distance-based fare structure adoption on horizontal equity was quantified in this study. Adopting an appropriate fare structure influences transit ridership and revenue and has a profound effect on social equity. This paper investigated the distance-based fare structure from the social equity point of view. Results indicate that the status of social equity under a distance-based fare structure conforms to the social equity much more than a flat-fare regime. Both the Gini index and the revenue-to-cost ratio explicitly show that disparity in the distribution of transit benefits decreases under a distance-based structure. For Isfahan, the value of the Gini 
index would reduce from 0.38 to 0.17 by switching to a distance-based fare structure. Moreover, the sum of the absolute deviation from 1 (perfect inequity) diminished from 22 (under a flat-fare structure) to 14 (under a proposed distance-based fare structure) shows more than a $50 \%$ improvement.

Results of this study could be used by bus transit organizations to set fares equitably and profitably. For Isfahan, setting the $F_{0}=\$ 0.033$ and $F_{1}=\$ 0.007$ would halve the Gini index and increase the revenue. It should be noted that any change in the operational cost of a bus system or the demand pattern may change these values. New values may be calculated using the formulations presented in the paper.

\section{Acknowledgment}

The authors would like to thank the reviewers for their meticulous review and helpful comments.

\section{References}

Cervero, R. 1981. "Flat versus Differentiated Transit Pricing: What's a Fair Fare?" Transportation, 10: 211-232.

Cervero, R. 1990. "Transit Pricing Research: A Review and Synthesis." Transportation, 17: 117-139.

Cervero, R. B., M. Wachs, R. Berlin, and R. J. Gephart. 1980. "Efficiency and Equity Implications of Alternative Transit Fare Policies." No. UMTA-CA-11-0019-80-1, Final Report.

Clements, H. 1997. "A New Way to Predict Transit Demand." Transportation Research Record, 23: 49-52.

Dargay, J., and M. Hanly. 1999. "Bus Fare Elasticities." Report to the UK Department of the Environment, Transport and the Regions. London, ESRC Transport Studies Unit, University College London, 132.

Farber, S., K. Bartholomew, X. Li, A. Páez, and K. M. N. Habib. 2014. "Assessing Social Equity in Distance Based Transit Fares Using a Model of Travel Behavior." Transportation Research Part A: Policy and Practice, 67, 291-303.

Goodwin, P. B. 1992. "A Review of New Demand Elasticities with Special Reference to Short and Long Run Effects of Price Changes." Journal of Transport Economics and Policy, 155-169.

Grey, A. 1975. Urban Fare Policy. Farnborough: Saxon House.

Horn af Rantzien, V., and A. Rude. 2014. "Peak-Load Pricing in Public Transport: A Case Study of Stockholm". Journal of Transport Literature, 8(1): 52-94.

Kain, J. F., and Z. Liu. 1999. "Secrets of Success: Assessing The Large Increases in Transit Ridership Achieved by Houston and San Diego Transit Providers." Transportation Research Part A: Policy and Practice, 33: 601-624. 
Linsalata, J., and L. H. Pham. 1991. "Fare Elasticity and Its Application to Forecasting Transit Demand." American Public Transit Association, Washington, DC.

Litman, T., 2002. "Evaluating Transportation Equity." World Transport Policy \& Practice, $8(2): 50-65$.

Litman, T. 2015. “Evaluating Public Transit Benefits and Costs." Victoria Transport Policy Institute.

Lovelock, C. H., G. Lewin, G. S. Day, and J. E. G. Bateson. 1987. Marketing Public Transit. New York: Praeger Publishers.

Marshall, A. 1920. Principles of Economics. London: London: Macmillan, reprinted by Prometheus Books.

Matthew, J. S. 2009. “Public Transit and the Time-Based Fare Structure.” Urban Transportation Center, University of Illinois at Chicago.

Nash, C. A. 1982. Economics of Public Transport. New York: Longman.

Nowak, W. P., and Savage I. 2013. "The Cross Elasticity between Gasoline Prices and Transit Use: Evidence from Chicago." Transit Policy, 29: 38-45.

Pucher, J. 1981. "Equity in Transit Finance: Distribution of Transit Subsidy Benefits and Costs among Income Classes." Journal of the American Planning Association, 47: $387-$ 407.

Ricciardi, A. M., J. Xia, and G. Currie. 2015. "Exploring Public Transport Equity between Separate Disadvantaged Cohorts: A Case Study in Perth, Australia." Journal of Transport Geography, 43: 111-122.

Sirikijpanichkul, A., and S. Winyoopadit. 2013. "Price Elasticity of Demand and Transit Fare Strategy: A Case Study of Bangkok Mass Transit System." Proceedings of the 4th International Conference on Engineering, Project, and Production Management (EPPM 2013), 346-360

Smith A. 2009. "Does the Quality of Public Transit Affect Commuters' Response to Gasoline Price Changes?" M.Sc. thesis, Duke University.

Taylor, B. D., and Camille N. Y. Fink. 2003. "The Factors Influencing Transit Ridership: A Review and Analysis of the Ridership Literature." University of California Transportation Center.

Taylor, B. D., and C. Fink. 2012. "Factors Influencing Transit Ridership: A Review and Analysis of the Ridership Literature." UCLA Department of Planning Working Paper.

Taylor, B. D., D. Miller, H. Iseki, and C. Fink. 2009. "Nature and/or Nurture? Analyzing the Determinants of Transit Ridership across US Urbanized Areas." Transportation Research Part A: Policy and Practice, 43: 60-77.

Wardman, M., and S. Grant-Muller. 2011. "Price Elasticities of Travel Demand in Great Britain: A Meta-Analysis." In Transportation Research Board 90th Annual Meeting (No. 11-3544). 
Webster, F. V., and P. H. Bly. 1980. "The Demand for Public Transport. Report of an International Collaborative Study." Transport and Road Research Laboratory, Crowthorne, Berkshire.

Welch, T. F. and S. Mishra. 2013. "A Measure of Equity for Public Transit Connectivity." Journal of Transport Geography, 33: 29-41.

\section{About the Authors}

MeisAm AKBARZADeh (makbarzadeh@cc.iut.ac.ir) is an Assistant Professor at the Isfahan University of Technology, Department of Transportation Engineering. His research areas of interest include public transportation and complex transportation networks.

MILAD BANDEGANI (miladbandegani@yahoo.com) is an MSc candidate at the Isfahan University of Technology, Department of Transportation Engineering. 